\title{
Recent Developments and Future Challenges in Designing Rechargeable Potassium-Sulfur and Potassium-Selenium Batteries
}

\author{
Suyeong Lee ${ }^{1}$, Jun Lee ${ }^{1}$, Jaekook Kim ${ }^{1}$, Marco Agostini ${ }^{2, *}$, Shizhao Xiong ${ }^{2}$, Aleksandar Matic ${ }^{2}$ \\ and Jang-Yeon Hwang 1 ,* \\ 1 Department of Materials Science and Engineering, Chonnam National University, Gwang-ju 61186, Korea; \\ gnoeyus2@gmail.com (S.L.); Jue6933@gmail.com (J.L.); jaekook@chonnam.ac.kr (J.K.) \\ 2 Department of Physics, Chalmers University of Technology, SE41296 Goteborg, Sweden; \\ shizhao.xiong@chalmers.se (S.X.); matic@chalmers.se (A.M.) \\ * Correspondence: agostini@chalmers.se (M.A.); hjy@jnu.ac.kr (J.-Y.H.)
}

Received: 28 February 2020; Accepted: 28 May 2020; Published: 1 June 2020

\begin{abstract}
The use of chalcogenide elements, such as sulfur (S) and selenium (Se), as cathode materials in rechargeable lithium $(\mathrm{Li})$ and sodium $(\mathrm{Na})$ batteries has been extensively investigated. Similar to $\mathrm{Li}$ and Na systems, rechargeable potassium-sulfur $(\mathrm{K}-\mathrm{S})$ and potassium-selenium (K-Se) batteries have recently attracted substantial interest because of the abundance of $K$ and low associated costs. However, K-S and K-Se battery technologies are in their infancy because $\mathrm{K}$ possesses overactive chemical properties compared to Li and $\mathrm{Na}$ and the electrochemical mechanisms of such batteries are not fully understood. This paper summarizes current research trends and challenges with regard to K-S and K-Se batteries and reviews the associated fundamental science, key technological developments, and scientific challenges to evaluate the potential use of these batteries and finally determine effective pathways for their practical development.
\end{abstract}

Keywords: potassium; K-S battery; K-Se battery; cathode; anode; electrochemical reaction

\section{Introduction}

Lithium ion (Li-ion) batteries (LIBs) dominate the current energy storage market. However, they have intrinsic limitations concerning the intercalation chemistry of their electrochemical storage mechanism, which effects their energy density. Thus, after decades of research and development, theoretical limits will be reached in the near future [1]. To further improve the energy density of LIBs, it is necessary to introduce new materials, in particular, those based on conversion reaction chemistry that have theoretical energy densities that are three to five times higher than those of commercially available LIBs. In this respect, sulfur (S) and selenium (Se) are very attractive candidates as they have low raw material costs, are highly abundant, and have low toxicities [2,3]. To guarantee a high energy density of the full cell, S- and Se-based electrodes need to be coupled with a high capacity anode material.

Recently, there has been growing interest in directly using lithium (Li) metal anodes. Indeed, the main advantages of Li metal are that it enables possibly infinite plating and has a very high specific capacity $\left(3830 \mathrm{mAh} \mathrm{g}^{-1}\right)$; therefore, its use with cathodes based on conversion chemistry can guarantee high volumetric and gravimetric energy densities [4]. However, there are concerns regarding the use of Li metal with respect to dendrite growth and high reactivity with the electrolyte, although these issues have been addressed by designing 3D structures hosting $\mathrm{Li}$ or by using protective surface additives that reduce the reactivity. In addition, there are critical concerns regarding the lack of natural abundance 
and geographical localization of Li sources, and the increasing demand for Li over the next few years is expected to increase its price; these are limiting factors that cannot easily be overcome [5].

In this respect, alternative metal anodes have recently begun to be investigated, in particular, the use of other alkali (but also alkaline earth) elements. Of these, potassium (K) offers certain unique advantages compared to sodium $(\mathrm{Na})$, calcium $(\mathrm{Ca})$, and magnesium $(\mathrm{Mg})$. First, $\mathrm{K}$ has a standard electric potential that is close to that of $\mathrm{Li}$ metal, $\left(\mathrm{Li}^{+} / \mathrm{Li}=-3.04 \mathrm{~V} ; \mathrm{K}^{+} / \mathrm{K}=-2.93 \mathrm{~V} ; \mathrm{Ca}^{2+} / \mathrm{Ca}=-2.87 \mathrm{~V}\right.$; $\mathrm{Na}^{+} / \mathrm{Na}=-2.71 \mathrm{~V}, \mathrm{Mg}^{2+} / \mathrm{Mg}=-2.27 \mathrm{~V}$; all vs. a standard hydrogen electrode (SHE)) [6], which allows rechargeable $\mathrm{K}$-ion batteries to operate at a high working voltage and exhibit a high energy density. Second, $\mathrm{K}$ is the seventh most abundant element within the Earth's crust and can be obtained at a low production cost. Consequently, the $\mathrm{K}$-metal anode has the potential to replace Li-metal anodes in future energy storage devices, particularly if it is coupled with high capacity elements such as $S$ and Se [7]. Figure 1 shows a schematic of the basic design of K-S (Figure 1A) and K-Se (Figure 1B) batteries.

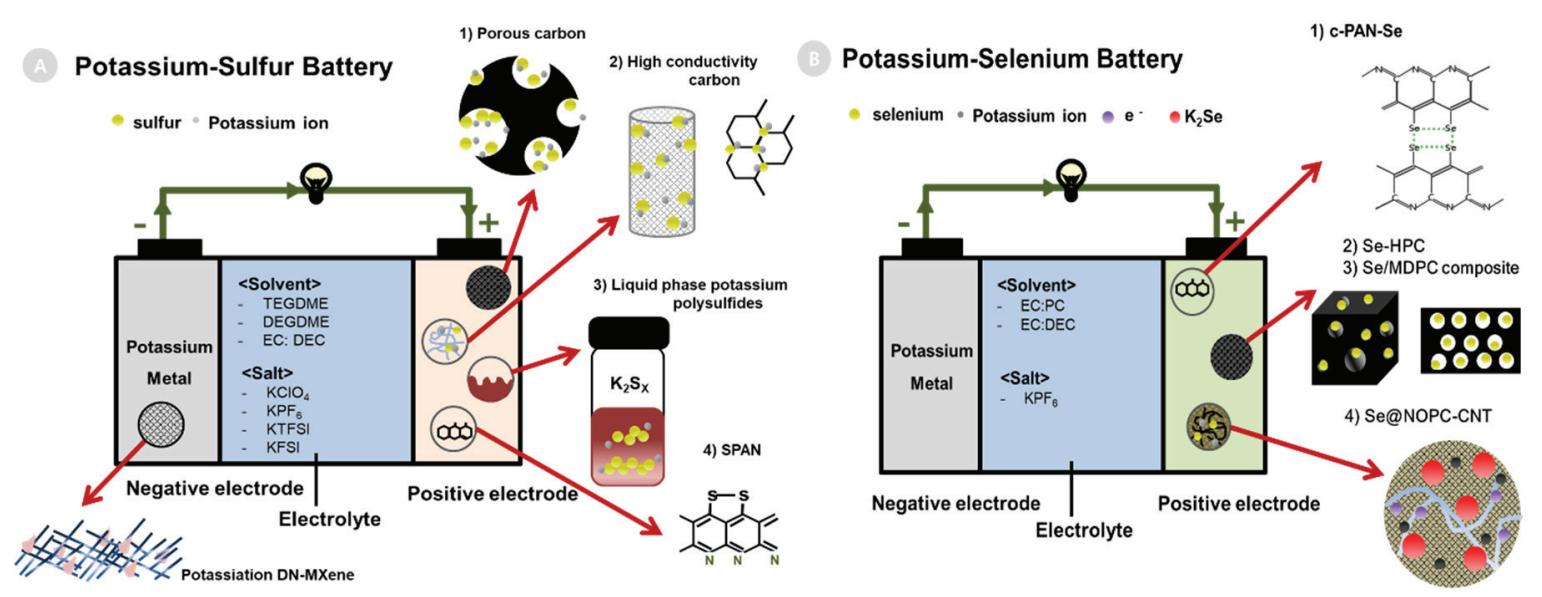

Figure 1. Schematic of rechargeable (A) potassium-sulfur (K-S) battery and (B) potassium-selenium (K-Se) battery.

K-S batteries have been developed in two main directions depending on the use of cathode materials: (1) elemental sulfur and (2) confined sulfur or covalent sulfur with polymer. However, $\mathrm{K}-\mathrm{S}$ batteries face the same issues as $\mathrm{Li}-\mathrm{S}$ and $\mathrm{Na}-\mathrm{S}$ batteries with respect to low utilization of the $\mathrm{S}$ active material, inferior cycle-life, and high reactivity of the $\mathrm{K}$ metal anode. The first concern is attributed to the electrically insulating nature of $S\left(5 \times 10^{-15} \mathrm{~S} \mathrm{~m}^{-1}\right)$, its dissolution as an intermediate polysulfide species $\left(\mathrm{K}_{2} \mathrm{~S}_{\mathrm{n}}\right)$, and the changes in volume upon an electrochemical reaction. Substantial efforts have been devoted to integrating $S$ in conductive hosts for promoting its utilization and confining soluble species in the working electrode surface $[6,8]$. Additional strategies and new cell configurations using a nonflammable potassium polysulfide $\left(\mathrm{K}_{2} \mathrm{~S}_{\mathrm{n}}\right)$ catholyte solution [9] or a solid electrolyte [10] have been proposed, and these have shown the possibility of attaining a safe $\mathrm{K}-\mathrm{S}$ battery configuration with a long cycle-life.

The K-Se battery is an additional and important concept that will likely be realized in the future owing to the high theoretical volumetric capacity of the Se electrode $\left(3250 \mathrm{mAh} \mathrm{cm}^{-3}\right)$ and its stable electrochemistry and high electronic conductivity $\left(1 \times 10^{-3} \mathrm{~S} \mathrm{~m}^{-1}\right)$ [11]. However, in addition to the above-mentioned issues concerning $\mathrm{K}-\mathrm{S}$ batteries, $\mathrm{K}-\mathrm{Se}$ batteries also exhibit problems associated with a low working voltage; in addition, they require state-of-the-art cell components that have not yet been adequately developed.

This review summarizes previous achievements made in $\mathrm{K}-\mathrm{S}$ and $\mathrm{K}-\mathrm{Se}$ battery designs and provides a comprehensive understanding of their associated fundamental science, electrochemical mechanisms, and prospective development in the future to inspire the development of novel, high-performing $\mathrm{K}-\mathrm{S}$ and $\mathrm{K}-\mathrm{Se}$ batteries. 


\section{Conventional K-S Batteries}

Although the K-S chemistry provides a lower theoretical energy density $\left(914 \mathrm{Wh} \mathrm{kg}^{-1}\right.$ based on $\mathrm{K}_{2} \mathrm{~S}$ formation) than Li-S (2600 Wh kg-1 based on $\mathrm{Li}_{2} \mathrm{~S}$ formation) [12,13], this new type of battery provides many advantages. The most positive advantages are that elemental abundances of both $S$ and $\mathrm{K}$ are high, their production costs are low, and they are environmentally friendly. However, unlike the Li-S and Na-S battery concepts, which have been extensively investigated over the last decade, only a few studies have described the K-S cell concept and mechanism [14].

In 2014, K-S batteries were first reported as a new battery technology, and this attracted immediate interest from the battery community [6]. The first K-S battery was constructed from ordered mesoporous carbon (CMK-3)/S and polyaniline (PANI) coated CMK-3/S composites as the cathode and metallic K as the anode. It was confirmed that $\mathrm{K}_{2} \mathrm{~S}_{3}$ was formed during discharge and reversed to $\mathrm{K}^{+}$and $\mathrm{S}$ for CMK-3/S electrode in the following charge [6] (Figure 2A). The electrochemical reaction mechanism of $\mathrm{CMK}-3 / \mathrm{S}$ electrode in K-S cell was proposed using the following equation.

$$
\begin{gathered}
\text { Discharge: } 3 \mathrm{~S}+2 \mathrm{~K}^{+}+2 \mathrm{e}^{-} \rightarrow \mathrm{K}_{2} \mathrm{~S}_{3} \\
\text { Charge: } \mathrm{K}_{2} \mathrm{~S}_{3}-2 \mathrm{e}^{-} \rightarrow 3 \mathrm{~S}+2 \mathrm{~K}^{+} \\
\text {Overall: } 3 \mathrm{~S}+2 \mathrm{~K} \leftrightarrow \mathrm{K}_{2} \mathrm{~S}_{3}
\end{gathered}
$$

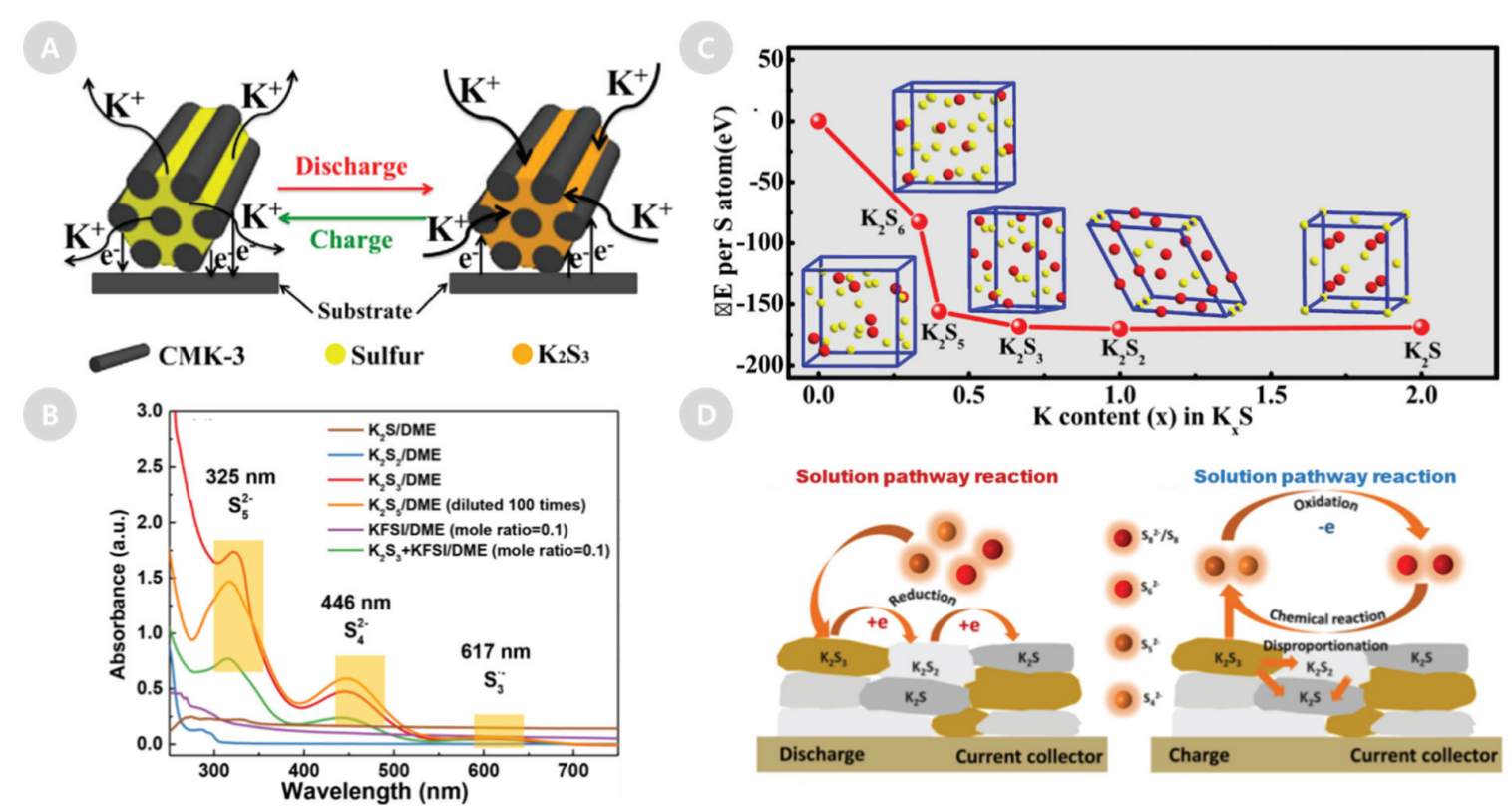

Figure 2. (A) Schematic of electrode reactions of rechargeable K-S batteries with CMK-3/S cathode. Figure adapted from Reference [6]. (B) Ultraviolet-visible (UV-vis) spectra of soluble phases of $\mathrm{K}_{2} \mathrm{~S}_{1} \mathrm{~K}_{2} \mathrm{~S}_{2}$, $\mathrm{K}_{2} \mathrm{~S}_{3}$, and $\mathrm{K}_{2} \mathrm{~S}_{5}$ in 1,2-dimethoxyethane (DME) and Potassium bis(fluorosulfonyl)imide(KFSI)-DME electrolytes. Figure adapted from Reference [15]. (C) Formation energies of potassium sulfides calculated via theoretical calculations. Figure adapted from Reference [16]. (D) The reaction mechanism for K-S batteries during cycling (left-side), the solid conversion reaction during discharging (middle) and the solution pathway reaction during charging (right-side). Figure adapted from Reference [15].

Unlike the unstable and soluble short-chain polysulfide intermediates formed in $\mathrm{Li}-\mathrm{S}$ and Na-S systems, the K-S cell exhibits the formation of a series of stable $\mathrm{K}_{2} \mathrm{~S}_{n}$ polysulfide phases $(\mathrm{n}=1,2,3,4,5,6)[15]$. The electrochemical mechanism, thermodynamic properties, and kinetics of the $\mathrm{K}-\mathrm{S}$ cell have been investigated by synthesizing both $\mathrm{K}_{2} \mathrm{~S}_{2}$ and $\mathrm{K}_{2} \mathrm{~S}_{3}$. Figure $2 \mathrm{~B}$ highlights the presence of $\mathrm{S}_{4}{ }^{2-}, \mathrm{S}_{5}{ }^{2-}$ and $\mathrm{S}_{3}{ }^{-}$(observed via ultraviolet-visible (UV-vis) absorption spectroscopy) when the 
$\mathrm{K}_{2} \mathrm{~S}_{3}$ species is dissolved in 1,2-dimethoxyethane (DME). An important aspect of the K-S mechanism is that the formation of the $\mathrm{K}_{2} \mathrm{~S}$ solid phase (as an end product of the $\mathrm{K}-\mathrm{S}$ reaction) is not reversible during battery operation. From density functional theory (DFT) calculations, it is evident that the $\mathrm{K}_{2} \mathrm{~S}$ phase exhibits the lowest formation energy, which suggests that it has a stable thermodynamic form, but $\mathrm{K}_{2} \mathrm{~S}_{2}$ exhibits a higher formation energy than $\mathrm{K}_{2} \mathrm{~S}_{3}$ and $\mathrm{K}_{2} \mathrm{~S}$. If $\mathrm{K}_{2} \mathrm{~S}_{2}$ is formed during an incomplete potassiation reaction, a disproportionate reaction can occur alongside the following reaction: $2 \mathrm{~K}_{2} \mathrm{~S}_{2}$ $\rightarrow \mathrm{K}_{2} \mathrm{~S}_{3}+\mathrm{K}_{2} \mathrm{~S}$; then, $\mathrm{K}_{2} \mathrm{~S}_{3}$ can be observed in the $\mathrm{K}-\mathrm{S}$ cell [16] (Figure 2C). However, a trace amount of soluble $\mathrm{K}_{2} \mathrm{~S}_{n}$ polysulfide can be transformed into high order $\mathrm{S}_{6}{ }^{2-}$, which can then shuttle through the separator and transform the insoluble $\mathrm{K}_{2} \mathrm{~S}_{\mathrm{n}}$ into a more soluble form, such as $\mathrm{S}_{4}{ }^{2-}$. The soluble species can subsequently diffuse to the carbon surface and be charged to high order polysulfide or to S. Unlike $\mathrm{K}_{2} \mathrm{~S}_{3}$ and $\mathrm{K}_{2} \mathrm{~S}_{2}, \mathrm{~K}_{2} \mathrm{~S}$ shows no oxidation or current, which indicates the lack of an electrochemical pathway; thus, it forms a "dead" species that no longer contributes to the reversible capacity. With respect to the information presented in this paragraph, the mechanism of the K-S cell is shown in Figure 2D.

A second important aspect of the K-S cell relates to possible active material loss during cycling. Similar to Li-S and Na-S cells, long chain K-polysulfide species can migrate to the anode side during charging and be deposited on the K-metal surface, which leads to a short cycle life. In this respect, the use of a $\mathrm{K}^{+}$-ion selective membrane based on Nafion- $\mathrm{K}^{+}$has been proposed to limit K-polysulfide diffusion upon charging. The membrane is placed between the cathode and the Celgard separator, and this has demonstrated a substantial suppression of $K_{2} S_{n}$ shuttling $[8,15]$.

A K-polysulfide catholyte was synthesized and used together with a self-standing supporting electrode in a novel K-S configuration [9]. A few series of $K_{2} S_{n}(n \geq 5)$ were then dissolved in diethylene glycol dimethyl ether (DEGDME), thereby forming a homogenous solution. The resulting solution was characterized by Raman spectroscopy and the presence of $\mathrm{K}_{2} \mathrm{~S}_{5}$ and $\mathrm{K}_{2} \mathrm{~S}_{6}$ was highlighted. Furthermore, the K-S semi liquid cell was used in electrochemical tests with a 3-dimensional (3D) freestanding carbon nanotube (3D FCN) based electrode. This electrode was tailored to have a high electrical conductivity and a porous structure, which provided 3D interlinked pathways for both $\mathrm{e}^{-}$ and $\mathrm{K}^{+}$. In the $\mathrm{K}$ half-cell, the working potential ranged between 1.2 and $2.4 \mathrm{~V}$ to avoid the shuttling reaction at the upper potential and the formation of $\mathrm{K}_{2} \mathrm{~S}_{2}$ and $\mathrm{K}_{2} \mathrm{~S}$ at the lower potential. By analyzing the discharge process through Raman spectroscopy and X-ray diffraction, a first peak in the CV at $2.1 \mathrm{~V}$ revealed the formation of long chain $\mathrm{K}_{2} \mathrm{~S}_{\mathrm{n}}$ polysulfides $(5 \leq \mathrm{n} \leq 6)$, whereas the subsequent peak at $1.8 \mathrm{~V}$ highlighted the reduction of the short chain $\mathrm{K}_{2} \mathrm{~S}_{\mathrm{n}}$ polysulfides to $\mathrm{K}_{2} \mathrm{~S}_{3}$. Raman spectroscopy also demonstrated the formation of $\mathrm{K}_{2} \mathrm{~S}_{5}$ after full charge (Figure 3A). This system delivered an initial capacity of $400 \mathrm{mAh} \mathrm{g}^{-1}$ at a current rate of $0.1 \mathrm{C}$ (Figure 3B). In general, the catholyte enabled faster kinetics and better reversibility compared to a solid sulfur electrode [6,9]. Recently, Yu et al. proposed the use of a Single-wall carbon nanotube (SWCNT) coating on the Celgard separator in $\mathrm{K}-\mathrm{S}$ batteries to mitigate the polysulfide-shuttle issue and increase the electrochemical utilization of $\mathrm{S}$, as the SWCNT coating material plays an important role in trapping the soluble K polysulfides. In addition, polysulfides species are effectively reduced or oxidized at the interface of the highly conductive SWCNT coating layer; therefore, the K \| Celgard/SWCNT \| S/Carbon nanofiber(CNF) cell showed a reversible discharge-charge process following the path (Figure 3C,D): $S_{8} \leftrightarrow K_{2} S_{6} \leftrightarrow K_{2} S_{4} \leftrightarrow$ $\mathrm{K}_{2} \mathrm{~S}_{2} \leftrightarrow \mathrm{K}_{2} \mathrm{~S}[8]$. 

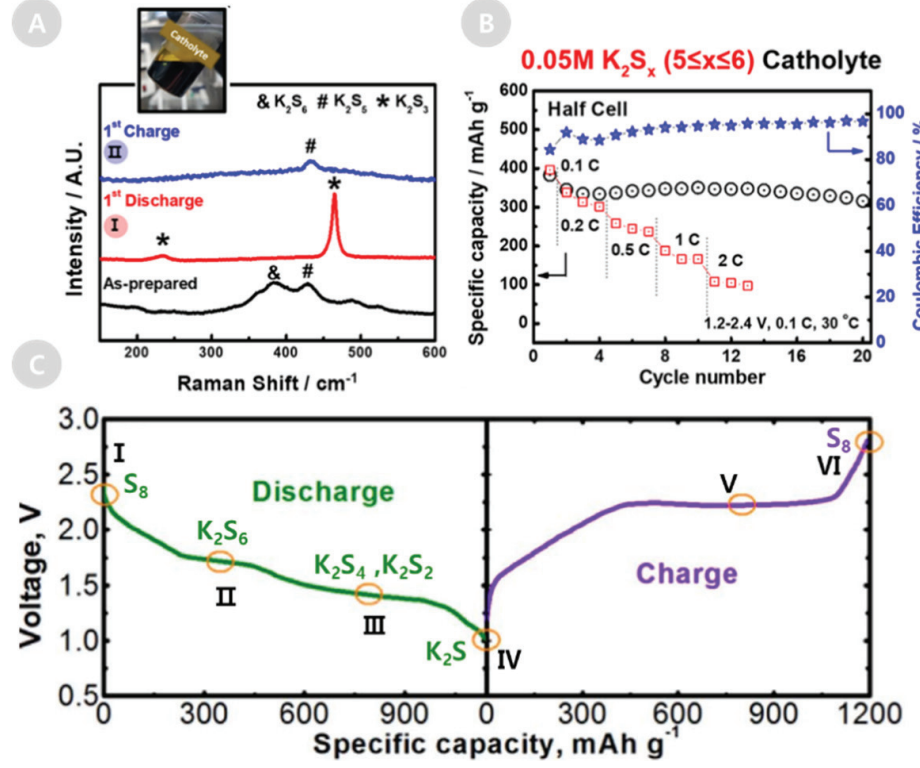

$0.05 \mathrm{M} \mathrm{K}_{2} \mathrm{~S}_{\mathrm{x}}(5 \leq \mathrm{x} \leq 6)$ Catholyte

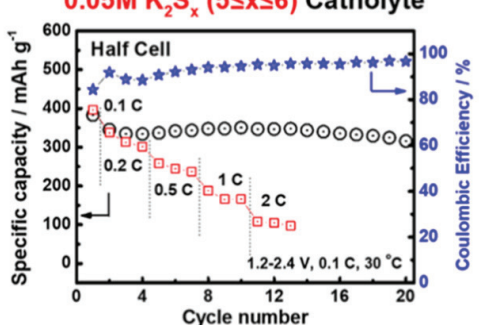

\section{.}

Figure 3. (A) Digital photograph of as-prepared $\mathrm{K}_{2} \mathrm{~S}_{\mathrm{x}}(5 \leq \mathrm{x} \leq 6)$ catholyte and Raman spectra at different state-of-charge (SOC) (black line: as-prepared; red line: discharge state at $1.8 \mathrm{~V}$; blue line: charge state at $2.4 \mathrm{~V})$. Figure adapted from Reference [9]. (B) Cycling and rate performance of a $\mathrm{K} \| \mathrm{K}_{2} \mathrm{~S}_{\mathrm{x}}(5 \leq \mathrm{x} \leq 6)$ catholyte $\|$ three-dimensional freestanding carbon nanotube (3D-FCN) cell. Figure adapted from Reference [9]. (C) Specific discharge-charge states in a voltage profile of the K $\|$ Celgard/SWCNT || S/CNF cell, from which samples were collected for XPS analysis. Figure adapted from Reference [8]. (D) XPS S 2p spectra of S electrodes being discharged or charged to different states in the K || Celgard/SWCNT || S/CNF cells. Figure adapted from Reference [8].

Based on the previous findings in the literature, it was found that conventional K-S batteries using elemental sulfur continue to face a critical challenge with respect to the reactivity of K-metal that usually limits the operation potential. Due to the insulating properties and slow reaction kinetics of solid sulfur, a large fraction of conductive host or matrix in the electrode material is required for improving the fast charging-discharging rate. To overcome these problems, novel electrode materials with high conductivity and high polysulfide affinity should be further developed. Moreover, the potassium-polysulfide dissolution damages the integrity and stability of the electrodes as well as induces stress-corrosion cracking in electrode materials of the K-S batteries. The static potassium-polysulfide diffusion can lead to severe self-discharge and short shelf life during cell resting. Therefore, analogues to Li-S battery, additives to produce an effective passivation film on the $\mathrm{K}$ metal anode should be further investigated. Finally, further detailed investigation is still needed to fully understand the charge-discharge mechanisms for successful operation of conventional K-S batteries.

\section{Confined and Covalent S to Realize a Stable K-S Battery}

The low electronic conductivity of $S$ requires composite electrodes to be designed with the addition of conductive materials to improve the electron transfer between the electrode/electrolyte interface during battery operation. A pyrolyzed polyacrylonitrile (PAN)-S nanocomposite (denoted as SPAN) was recently reported to be compatible with a stable carbonate electrolyte in Li-S systems [17]. In addition, owing to the covalent and confined S in the SPAN structure (Figure 4A), neither polysulfide dissolution phenomena nor a detrimental shuttle effect was observed. As researchers have subsequently attempted to test the performance of the SPAN in room temperature K-S batteries, the electrochemical performance of the SPAN cathode in K-S batteries has been better investigated $[7,17,18]$. 

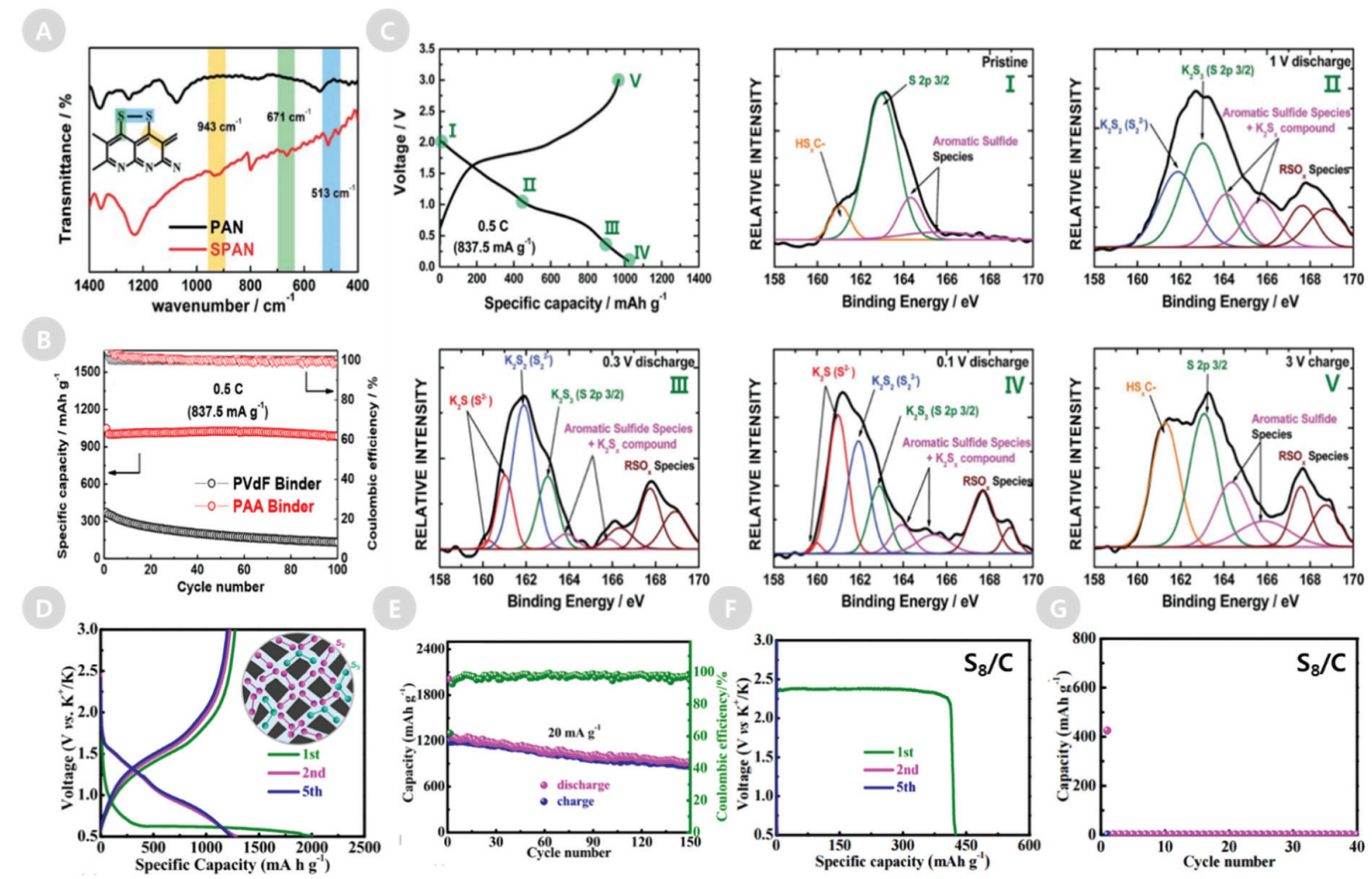

Figure 4. (A) Results of FT-IR analysis of polyacrylonitrile (PAN) and a sulfurized polyacrylonitrile nanocomposite (SPAN) structure. Figure adapted from Reference [18]. (B) Comparison of cycle life of SPAN electrode depending on binder. Figure adapted from Reference [18]. (C) Charge-discharge voltage profiles and XPS analysis of SPAN electrode with polyacrylic acid (PAA) binder at different states of charge: pristine, discharged at $1 \mathrm{~V}$, discharged at $0.3 \mathrm{~V}$, discharged at $0.1 \mathrm{~V}$, and charged at $3 \mathrm{~V}$. Figure adapted from Reference [18]. Comparison of (D,F) charge-discharge profiles and (E,G) cycling stabilities of the micro porous structured C/S composite and conventional S/C composite electrodes. Figure adapted from Reference [16].

In 2018, Liu et al. first suggested a K-S battery with SPAN as a positive electrode, and they evaluated the performance of SPAN in $0.8 \mathrm{M} \mathrm{KPF}_{6}$ in an EC: DEC $(1: 1 v / v)$ electrolyte using metallic K as counter/reference electrode [17]. The galvanostatic response of the SPAN/K cell (at $0.5 \mathrm{C}$ ) indicated that the first discharge requires an activation process, such as the cleavage of $\mathrm{C}-\mathrm{S}$ bonds and the rearrangement of $S$ atoms. In addition, the voltage profiles exhibited an irreversible capacity during the first cycle from the decomposition of the electrolyte and the formation of a solid electrolyte interphase. After the first cycle, the galvanostatic profiles of the second and third cycles overlapped and exhibited a stable reversible capacity in a carbonate-based electrolyte that minimizes the dissolution of the $\mathrm{K}_{2} \mathrm{~S}_{n}$ polysulfide species. This result clearly indicated that a K-S battery using a SPAN cathode could enhance cycle stability through optimization of the composition of the electrolyte, whereas the SPAN morphology could alleviate the decomposition of the electrolyte reducing polarization reactions. Based on ex-situ Raman and XPS spectroscopy, Liu et al. reported that the C-S bond was broken during the discharge of the SPAN electrode but was then reformed after charging; however, the decrease in the intensity of the C-S Raman peaks indicated that the process was not fully reversible [17]. In 2018, Hwang et al. reported a different approach for designing an advanced SPAN electrode to improve the electrochemical performances of K-S batteries [18]. The electrode was fabricated using a different type of polymer binder, polyacrylic acid (PAA). The PAA binder, which has already been reported on with respect to Si-based anodes, has an important role in providing the active material with better uniformity and a stronger binding ability. The electrode that employed a PAA binder was compared to a standard SPAN electrode using polyvinylidene fluoride (PVdF). Based on cyclic voltammetry experiments, it was found that the SPAN/PAA electrode showed highly reversible redox reactions, and reversible 
reformation of the C-S bond was observed upon cycling, in contrast to SPAN/PVdF. The cycling performances of both electrodes were compared using a current rate of $0.5 \mathrm{C}$. SPAN/PAA achieved a reversible capacity of $1050 \mathrm{mAh} \mathrm{g}^{-1}$ during the first cycle and a $95 \%$ capacity retention after 100 cycles, whereas the SPAN/PVdF electrode showed a very low capacity of $370 \mathrm{mAh} \mathrm{g}^{-1}$ in the first cycle and only $22 \%$ retention after 100 cycles (Figure $4 \mathrm{~B}$ ). Based on the XPS data, the charge-discharge mechanism of the SPAN electrode in the K-system was proposed using the following equation (Figure 4C) [18],

Discharge process

$$
\begin{gathered}
-\mathrm{C}-\mathrm{SK}+\mathrm{K}^{+}+\mathrm{e}^{-} \rightarrow-\mathrm{C}+\mathrm{K}_{2} \mathrm{~S} \\
-\mathrm{C}-\mathrm{SK}+2 \mathrm{~K}^{+}+2 \mathrm{e}^{-} \rightarrow-\mathrm{C}^{-} \mathrm{K}^{+}+\mathrm{K}_{2} \mathrm{~S}
\end{gathered}
$$

Charge process

$$
-\mathrm{C}+\mathrm{K}_{2} \mathrm{~S} \rightarrow-\mathrm{C}-\mathrm{SK}+\mathrm{K}^{+}+\mathrm{e}^{-}
$$

The authors also suggested an optimum operation voltage of 1.0-3.0 V for the SPAN electrode in the $\mathrm{K}-\mathrm{S}$ cell. Tang et al. developed an advanced K-S battery with a SPAN cathode and a modified K-metal anode [7]. Their research initially focused on the K-S anode, with the aim of reducing K-reactivity and shuttling of the polysulfide species. A defect-rich and nitrogen-containing MXene/carbon nanotube (CNT) freestanding scaffold was developed as a metallic K anode with a homogeneous CNT distribution in the DN-MXene sheet. The K@DN-MXene/CNT metal anode was found to be able to suppress dendritic growth and protect the K-metal surface from $\mathrm{S}$ deposition, leading to improvements in electrochemical performance and cycle-life. Using the K@DN-MXene/CNT composite as the anode and the SPAN as the cathode in a $\mathrm{KPF}_{6}$-based carbonate electrolyte, an enhanced specific capacity and cycle-life were demonstrated. The cell showed an impressive specific capacity of $113 \mathrm{mAh} \mathrm{g}^{-1}$ at a very high current rate of $5 \mathrm{C}$ as well as a specific capacity of $230 \mathrm{mAh} \mathrm{g}^{-1}$ at $0.5 \mathrm{C}$ after 500 cycles. Similar to the SPAN cathode, $\mathrm{K}-\mathrm{S}$ batteries have recently been realized using microporous carbon-confined small-molecule $S$ cathode materials [16]. The unique microporous structured $C / S$ composite has been found to completely eliminate the formation of soluble polysulfides; thus, it shows a better cycling stability than conventional C/S composite materials (Figure $4 D, G$ ).

\section{K-Se Batteries}

Se is an alternative element for K-metal batteries that has recently attracted substantial attention as a replacement for $\mathrm{S}$. In the family of chalcogenides, Se is a neighboring element of S; therefore, its electrochemical reaction with $\mathrm{K}$ is likely to be similar to that of $\mathrm{S}$ with $\mathrm{K}$. Compared to $\mathrm{S}$, Se possesses a similar high theoretical volumetric capacity (Se: $3253 \mathrm{~mA} \mathrm{~h} \mathrm{~cm}{ }^{-3}$ vs. S: $3467 \mathrm{mAh} \mathrm{cm}^{-3}$ ) but a relatively low theoretical specific capacity (Se: $675 \mathrm{mAh} \mathrm{g}^{-1}$ vs. S: $1675 \mathrm{mAh} \mathrm{g}^{-1}$ ), owing to its high molar mass. Se has a higher electrical conductivity than S (Se: $1 \times 10^{-4} \mathrm{~S} \mathrm{~m}^{-1}$ vs. S: $5 \times 10^{-15} \mathrm{~S} \mathrm{~m}^{-1}$ ) and is less reactive with $\mathrm{K}$ metal; therefore, studies have been conducted on the use of Se in rechargeable K batteries $[4,11,19,20]$.

A K-Se cell provides a volumetric energy density that is comparable with that of a K-S cell, but it has a higher gravimetric energy density than K-ion batteries [11]. Nevertheless, the K-Se battery has also been plagued by issues concerning short cycle life and low charging efficiency (caused by the dissolution of intermediate polyselenides) as well as a large volume expansion during the charge/discharge process. Liu et al. proposed a reversible K-Se battery by confining Se in a carbonized-polyacrylonitrile composite (c-PAN-Se) [11]. The c-PAN-Se composite was simply fabricated via direct heating of a mixture of Se and PAN $\left(\sim 60{ }^{\circ} \mathrm{C}\right)$. In contrast with the case of simply adding Se to the c-PAN, the c-PAN-Se composite revealed a unique structure with covalently bonded Se (Figure 5A), and Se formed covalent bonds with carbon atoms or Se local domains consisting of Se chains of various lengths (Figure 5B). In the heat-treatment process of the PAN and Se mixture, elemental Se was turned into Se free radicals, which then reacted with the PAN-derived carbon matrix. Se was thus uniformly distributed in the PAN and/or a small molecule called Se1 was confined in the c-PAN matrix. This unique chemical structure enables the formation of reversible small molecules of Se1, which essentially inhibits the 
formation of polyselenides during a repeated charge-discharge process. Hence, the shuttle effect is inhibited for the c-PAN-Se composite cathode in carbonate electrolytes $\left(1 \mathrm{M} \mathrm{KPF}_{6}\right.$ dissolved in EC:PC $(1: 1 v / v))$, showing good reversibility of the charge-discharge process. Based on high energy XRD and in situ Raman spectroscopic analysis, it was proposed that the charge-discharge reaction of this K-Se cell was a reversible $\mathrm{Se}+2 \mathrm{~K}^{+} \leftrightarrow \mathrm{K}_{2}$ Se conversion reaction (Figure 5C). A comparison between a pure Se and a c-PAN + Se cathode showed that the c-PAN-Se cathode exhibited superior electrochemical properties; specifically, a reversible capacity of $1904 \mathrm{mAh} \mathrm{cm}^{-3}\left(396 \mathrm{mAh} \mathrm{g}^{-1}\right)$ after 100 cycles at $0.2 \mathrm{C}$ and a rate retention of $89 \%$ from 0.1 to $2 \mathrm{C}$ were obtained.

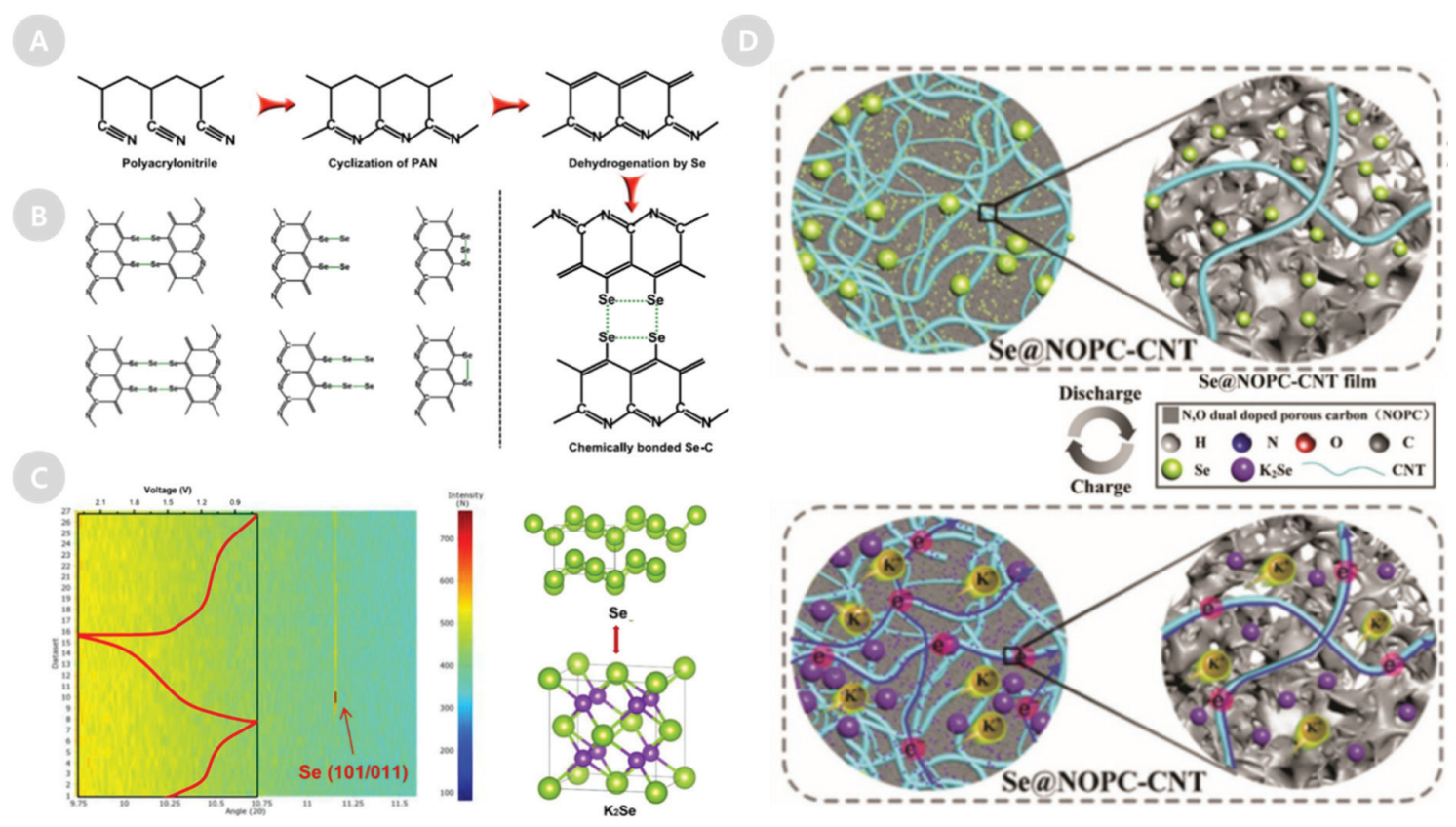

Figure 5. (A) Reaction mechanism and changes in the molecular structure during the carbonization of PAN and selenization between Se and c-PAN. Figure adapted from Reference [11]. (B) Possible molecular structures of the as-prepared chemically bonded Se/C composite. Figure adapted from Reference [11]. (C) In-situ synchrotron X-ray diffraction(XRD) spectra with corresponding voltage profile and structural representations of $\mathrm{Se}$ and $\mathrm{K}_{2}$ Se phases during discharge-charge process. Figure adapted from Reference [11]. (D) Schematic of the K-ion and electron transportation process in the nitrogen and oxygen dual-doped Se@NOPC-CNT electrode when used in K-Se batteries. Figure adapted from Reference [3].

Yao et al. proposed a different type of K-Se battery by fabricating carbon nanotube (CNT) interwoven $\mathrm{N}$, O-dual doped porous carbon nanosheets and physically encapsulating and confining Se [4]. The unique Se@NOPC-CNT electrode design exhibited advantages that enhanced the areal loading of Se and mitigated the shuttling effect of $\mathrm{K}$ ions. The presence of heteroatom doping $(\mathrm{N}, \mathrm{O})$ in the carbon skeleton produced abundant surface anchoring sites for trapping the polyselenides and prevented their migration to the anode side (Figure 5D). The enhancement of the chemical affinity was evaluated by calculating the binding energy between the polar $\mathrm{K}_{\mathrm{x}} \mathrm{Se}(0<\mathrm{x} \leq 2)$ and chemical-modified porous carbon using a DFT calculation. The Se@NOPC-CNT electrode showed a high reversible capacity (544 mAh g-1 after 150 cycles at $\left.0.1 \mathrm{~A} \mathrm{~g}^{-1}\right)$, a superior rate capability $\left(273 \mathrm{mAh} \mathrm{g}^{-1}\right.$ at $\left.5 \mathrm{~A} \mathrm{~g}^{-1}\right)$, and an excellent cycling stability $\left(335 \mathrm{mAhg}^{-1}\right.$ after 700 cycles at $\left.0.8 \mathrm{Ag}^{-1}\right)$ in K-Se batteries. Compared to the c-PAN-Se electrode, the Se@NOPC-CNT electrode had a larger content of Se active material (i.e., $60 \mathrm{wt} \%$ ), a better cycling life, and a remarkable delivered capacity [4]. Very recently, Huang et al. proposed the design of an Se/nitrogen-doped porous carbon composite electrode using a hollow structure that provides sufficient space to accommodate large amounts of Se atoms/ions and has a high electronic conductivity that guarantees a good electrochemical performance. Other studies considered 
that the presence of a void space could alleviate volume expansion issues during the reaction of Se and $\mathrm{K}[19,20]$.

\section{Conclusions}

Although K-S/Se batteries have been researched in several studies, the electrochemical redox reaction and the chemical compositions of the charge-discharge products have not yet been elucidated. In addition, the development of appropriate electrodes, electrolytes, and the other components used in these battery systems remains in its infancy. Hence, further efforts are required to accelerate the development of K-S and K-Se batteries and promote research that focuses on protecting the cathode structure, blocking soluble polysulfides, and stabilizing the $\mathrm{K}$ anode. In particular, based on knowledge from $\mathrm{Li}-\mathrm{S}$ and Na-S cells [21,22], it is important to re-design $\mathrm{K}-\mathrm{S}$ and $\mathrm{K}-\mathrm{Se}$ cathodes by including functional groups at their surfaces. Oxide and metal particles [23], metal organic frameworks [24], and metal nitrides [25] have been shown to be promising pathways for improving the binding energy of sulfidic phases at the cathode side. However, Se-based electrodes are more conductive than those based on S, and they mostly do not require a large amount of the carbon host, although the carbon host needs to be tailored to have larger pores, owing to its larger size. Protecting polysulfides and polyselenides from shuttling is also an important research direction that needs to be pursued to improve the cycle-life of K-S and K-Se cells. Previous achievements in this regard have been made by making modifications at the separator [26]. For example, it has been demonstrated that including CNTs or a Nafion thin layer reduces polysulfide shuttling and improves battery performance. In addition, possible protection of the K-metal surface is also required [8,15], and only a few studies have reported additives that can protect the surface of the $\mathrm{K}$ metal. In particular, with respect to the $\mathrm{K}-\mathrm{S}$ battery, a considerable amount of research is required to find electrolyte additives that are analogous to those of $\mathrm{Li}-\mathrm{S}$ cells.

Author Contributions: J.-Y.H. conceived the idea. S.L. J.-Y.H. and M.A. prepared the manuscript. A.M. J.L. J.K. and S.X. reviewed and edited the structure of the review paper. All authors have read and agreed to the published version of the manuscript.

Funding: This work was supported by the National Research Foundation of Korea grant funded by the Korea Government Ministry of Education and Science Technology (NRF-2018R1A5A 1025224) and (NRF-2019R1F1A1063538). This work was supported by STINT and NRF in a joint Korea-Sweden program (2020K2A9A2A12000231).

Conflicts of Interest: The authors declare no conflict of interest.

\section{References}

1. Li, M.; Lu, J.; Chen, Z.; Amine, K. 30 Years of lithium-ion batteries. Adv. Mater. 2018, 30, 1800561. [CrossRef] [PubMed]

2. Service, R.F. Lithium-sulfur batteries poised for leap. Science 2018, 359, 1080-1081. [CrossRef] [PubMed]

3. Yao, Y.; Chen, M.; Xu, R.; Zeng, S.; Yang, H.; Ye, S.; Liu, F.; Wu, X.; Yu, Y. CNT interwoven nitrogen and oxygen dual-doped porous carbon nanosheets as free-standing electrodes for high-performance Na-Se and K-Se flexible batteries. Adv. Mater. 2018, 30, 1805234. [CrossRef] [PubMed]

4. Lin, D.; Liu, Y.; Cui, Y. Reviving the lithium metal anode for high-energy batteries. Nat. Nanotechnol. 2017, 12, 194-206. [CrossRef]

5. Cheng, X.B.; Zhang, R.; Zhao, C.Z.; Zhang, Q. Toward safe lithium metal anode in rechargeable batteries: A Review. Chem. Rev. 2017, 117, 10403-10473. [CrossRef]

6. Zhao, Q.; Hu, Y.; Zhang, K.; Chen, J. Potassium-sulfur batteries: A new member of room-temperature rechargeable metal-sulfur batteries. Inorg. Chem. 2014, 53, 9000-9005. [CrossRef]

7. Tang, X.; Zhou, D.; Li, P.; Guo, X.; Sun, B.; Liu, H.; Yan, K.; Gogotsi, Y.; Wang, G. MXene-based dendrite-free potassium metal batteries. Adv. Mater. 2019, 32, 1906739. [CrossRef]

8. Yu, X.; Manthiram, A. A reversible nonaqueous room-temperature potassium-sulfur chemistry for electrochemical energy storage. Energy Storage Mater. 2018, 15, 368-373. [CrossRef]

9. Hwang, J.-Y.; Kim, H.M.; Yoon, C.S.; Sun, Y.-K. Toward high-safety potassium-sulfur batteries using a potassium polysulfide catholyte and metal-free anode. ACS Energy Lett. 2018, 3, 540-541. [CrossRef] 
10. Lu, X.; Bowden, M.E.; Sprenkle, V.L.; Liu, J. A low cost, high energy density, and long cycle life potassium-sulfur battery for grid-scale energy storage. Adv. Mater. 2015, 27, 5915-5922. [CrossRef]

11. Liu, Y.; Tai, Z.; Zhang, Q.; Wang, H.; Pang, W.K.; Liu, H.K.; Konstantinov, K.; Guo, Z. A new energy storage system: Rechargeable potassium-selenium battery. Nano Energy 2017, 35, 36-43. [CrossRef]

12. Manthiram, A.; Fu, Y.; Chung, S.-H.; Zu, C.; Su, Y.-S. Rechargeable lithium-sulfur Batteries. Chem. Rev. 2014, 114, 11751-11787. [CrossRef] [PubMed]

13. Kumar, R.; Liu, J.; Hwang, J.-Y.; Sun, Y.-K. Recent research trends in Li-S batteries. J. Mater. Chem. A 2018, 6, 11582-11605. [CrossRef]

14. Hwang, J.-Y.; Myung, S.T.; Sun, Y.-K. Recent progress in rechargeable potassium batteries. Adv. Funct. Mater. 2018, 28, 1802938. [CrossRef]

15. Gu, S.; Xiao, N.; Wu, F.; Bai, Y.; Wu, C.; Wu, Y. Chemical synthesis of $\mathrm{K}_{2} \mathrm{~S}_{2}$ and $\mathrm{K}_{2} \mathrm{~S}_{3}$ for probing electrochemical mechanisms in K-S Batteries. ACS Energy Lett. 2018, 3, 2858-2864. [CrossRef]

16. Xiong, P.; Han, X.; Zhao, X.; Bai, P.; Liu, Y.; Sun, J.; Xu, Y. Room-temperature potassium-sulfur batteries enabled by microporous carbon stabilized small-molecule sulfur cathodes. ACS Nano 2019, 13, 2536-2543. [CrossRef]

17. Liu, Y.; Wang, W.; Wang, J.; Zhang, Y.; Zhu, Y.; Chen, Y.; Fu, L.; Wu, Y. Sulfur nanocomposite as a positive electrode material for rechargeable potassium-sulfur batteries. Chem. Commun. 2018, 54, 2288-2291. [CrossRef] [PubMed]

18. Hwang, J.-Y.; Kim, H.M.; Sun, Y.-K. High performance potassium-sulfur batteries based on sulfurized polyacrylonitrile cathode and polyacrylic acid binder. J. Mater. Chem. A 2018, 6, 14587-14593. [CrossRef]

19. Huang, X.; Wang, W.; Deng, J.; Gao, W.; Liu, D.; Ma, Q.; Xu, M. A Se-hollow porous carbon composite for high performance rechargeable K-Se batteries. Inorg. Chem. Front. 2019, 6, 2118-2125. [CrossRef]

20. Huang, X.; Xu, Q.; Gao, W.; Yang, T.; Zhan, R.; Deng, J.; Guo, B.; Tao, M.; Liu, H.; Xu, M. Rechargeable K-Se batteries based on metal-organic-frameworks-derived porous carbon matrix confined selenium as cathode materials. J. Colloid Interface Sci. 2019, 539, 326-331. [CrossRef]

21. Marco, A.; Matic, A. Designing highly conductive functional groups improving guest-host interactions in Li/S batteries. Small 2019, 16, 1905585.

22. Manthiram, A.; Yu, X. Ambient temperature sodium-sulfur batteries. Small 2015, 11, 2108-2114. [CrossRef] [PubMed]

23. Hwang, J.-Y.; Kim, H.M.; Lee, S.-K.; Lee, J.-H.; Abouimrane, A.; Khaleel, M.A.; Belharouak, I.; Manthiram, A.; Sun, Y.-K. High-energy, high-rate, lithium-sulfur batteries: Synergetic effect of hollow $\mathrm{TiO}_{2}$-webbed carbon nanotubes and a dual functional carbon-paper interlayer. Adv. Energy Mater. 2016, 6, 1501480. [CrossRef]

24. Zheng, Y.; Zheng, S.; Huaiguo, X.; Pang, H. Metal-organic frameworks for lithium-sulfur batteries. J. Mater. Chem. A 2019, 7, 3469-3491. [CrossRef]

25. Chen, Z.; Lv, W.; Kang, F.; Li, J. Theoretical investigation of the electrochemical performance of transition metal nitrides for lithium-sulfur batteries. J. Phys. Chem. C 2019, 123, 25025-25030. [CrossRef]

26. Hwang, J.-Y.; Kim, H.M.; Shin, S.-B.; Sun, Y.-K. Designing a high performance lithium-sulfur batteries based on layered double hydroxides-carbon nanotubes composite cathode and a dual-functional graphenepolypropylene- $\mathrm{Al}_{2} \mathrm{O}_{3}$ separator. Adv. Funct. Mater. 2018, 28, 1704294. [CrossRef]

(C) 2020 by the authors. Licensee MDPI, Basel, Switzerland. This article is an open access article distributed under the terms and conditions of the Creative Commons Attribution (CC BY) license (http://creativecommons.org/licenses/by/4.0/). 